\title{
UNA PROPUESTA VOCACIONAL PARA LA PASTORAL JUVENIL
}

\section{DOI: https://doi.org/10.52039/seminarios.v50i174.754}

Autor: Vicente Zueco. Sacerdote Op rario Diocesano. Director del IPV de Buenos Aires

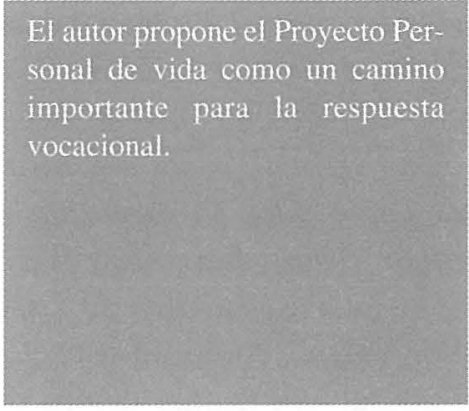

1.- Proyecto de vida: Camino vocacional de la pastoral juvenil latinoamericana

Así se titula el Documento del Celam no 162 publicado a finales del 2003: "Proyecto de vida: Camino vocacional de la pastoral juvenil latinoamericana". Es el fruto maduro de todo un itinerario cumplido por la Pastoral Juvenil a nivel latinoamericano. Después del II Congreso Latinoamericano de Jóvenes en Punta de Tralca, Chile, 1996, en los Encuentros Latinoamericanos de Responsables de Pastoral Juvenil en Argentina (febrero de 2001) y Ecuador (febrero 2003), se profundizó sobre los Procesos de Educación en la Fe, y la Militancia, en relación con el Proyecto de Vida.

En esta publicación intentan releer las propuestas presentadas en el libro "Civilización del Amor, Tarea y esperanza" (1995), desde este nuevo enfoque vocacional que ha aparecido y madurado en estos últi- 
mos años. "La Vocacionalidad es una de las dimensiones de la Pastoral Juvenil que no ha obtenido todavía su merecido espacio en nuestra reflexión pastoral. Con ella entendemos algo más amplio que la "promoción vocacional", normalmente más preocupado por el llamado a la vida religiosa o sacerdotal que por la vocacionalidad propia de la persona cristiana". "Queremos también provocar un camino de reflexión que nos despierte y abra hacia nuevos horizontes. ¿Cómo? Profundizando aspectos fundamentales: la Vocacionalidad, el Proyecto de vida y la Militancia".

"Con la presente reflexión queremos resaltar la dimensión vocacional de la Pastoral Juvenil. Si la Iglesia es la asamblea de los convocados por el Padre para vivir y anunciar con Cristo y el Espíritu Santo el don del Reino de Dios, la Pastoral Juvenil está llamada a ser el almácigo en el que se siembra, cuida y crece la semilla de la vocación personal, cuyo descubrimiento y posterior aceptación y vivencia es clave para la extensión y afianzamiento de la Civilización del Amor” (Mns. Bargalló y P. Armelín en el Prólogo).

La Pastoral Juvenil Latinoamericana presenta el "PROYECTO DE VIDA" como un aspecto concreto, instrumental y preciso de la Pastoral Vocacional dentro de las opciones pedagógicas con que se encaran los procesos de educación en la fe y la militancia.

\section{2.- Del reclutamiento vocacional a la misión compartida}

La verdad es que hacia los años 40 fueron muchas las vocaciones que surgieron de la entonces floreciente Acción Católica. Con la invitación de Juan XXIII a las iglesias europeas para que enviasen agentes de pastoral, muchas diócesis se confiaron en la ayuda de sacerdotes y religiosos venidos de fuera. Los que llegamos a A.L. en aquellos años teníamos muy claro que nuestra tarea no era de suplencia, sino de formar agentes multiplicadores.

Por eso se abrieron seminarios y casas de formación, escuelas de catequesis, escuelas de ministerios, etc.

En el florecimiento vocacional que comienza en los años 50 podemos distinguir varias etapas que en parte coinciden con fenómenos similares en todas las iglesias: 
Comenzó así una época de "reclutamiento vocacional". La pastoral vocacional consistía en abastecer de vocaciones sacerdotales y religiosas (preferentemente de preadolescentes) los seminarios y casas de formación. Esta etapa sigue funcionando todavía en las zonas más pobres y con menos oportunidades económicas o profesionales.

Después vino la "pastoral juvenil vocacional" que se entendió de dos maneras diferentes:

1. A unos les pareció que se trataba de poner un marco a la pastoral vocacional tradicional; es decir, había que desarrollar la pastoral juvenil para realizar luego en ella el "reclutamiento" de las vocaciones sacerdotales o consagradas.

2. Otros comprendieron (y bien) que la pastoral juvenil era la nueva identidad de la pastoral vocacional; es decir, el esfuerzo había que p snerlo en desarrollar la pastoral juvenil, pero con la dimensión vocacional, de principio al fin de los procesos pastorales de la PJ, de modo que cada joven pudiera encontrar su específica vocación cristiana, como la forma de vivir el seguimiento de Jesús.

Si bien la pastoral vocacional no se agota, ni mucho menos, en la Pastoral Juvenil, la juventud es el "kairos vocacional", es el tiempo en que se hacen las grandes opciones vocacionales. Es el tiempo en que se puede responder a estas dos preguntas fundamentales ¿Quién soy? ¿Qué quiero ser? Desde la sicología evolutiva y los procesos de fe, éste es el momento oportuno, aunque Dios llama cuando quiere y todas las etapas de la vida tienen su dimensión vocacional.

\section{3.- Ecología vocacional}

La propuesta actual es que, tanto en la pastoral juvenil, como en los otros ámbitos donde se desarrolla la pastoral vocacional, ésta se realice en función de "una misión compartida". Es decir, la vocación se presenta en un nuevo contexto de interrelación entre las diferentes identidades eclesiales en torno a la misión, señalando así su motivación central, que no es otra que la misión de la Iglesia, al servicio de la cual están todas las vocaciones. Dios nos llama para la misión, y la Iglesia nos convoca para la misión, para la evangelización.

También para la vocación sirve el concepto de globalización, que solemos expresar hablando de una Iglesia "toda ella vocacional". Esto 
nos impone una mentalidad "holística". Todas las vocaciones son importantes en la Iglesia, todas necesarias para la evangelización. Pero al mismo tiempo hemos de tener una mentalidad "ecológica". Cuando desaparece, o escasea una vocación, las otras también se resienten. Algunos hablan, por ejemplo, que en algunos lugares de Europa ya no se puede hablar de escasez de sacerdotes. Hay escasez de laicos. La mayoría de los sacerdotes atienden a la mitad de fieles que la que atendían hace 20 años. No hay laicos, no hay vocaciones laicales (Greshake en "Ser sacerdote hoy" Sígueme 2003).

Estamos ante un nuevo "ecosistema" eclesial que es muy diferente al de hace unos años, también en Latinoamérica, aunque el proceso es más lento. La supervivencia de la Pastoral Vocacional depende de su capacidad de adaptarse a este nuevo ecosistema.

Hay algunos que, frente a estos desafíos, prefieren mirar al pasado e imitar los tiempos gloriosos de la pastoral vocacional. Repiten o readaptan métodos que, a la corta o a la larga, no dan resultado. Así estamos comprobando que en muchos agentes de pastoral vocacional se produce lo que el Papa llama "la patología del cansancio". Hacen una Pastoral Vocacional que ya está perimida.

Algunos se deslumbran ante el aparente éxito que tienen los que se han refugiado en una actitud militantemente reaccionaria a los cambios.

De hecho hay muy pocas "novedades" en pastoral vocacional. Las que hay, casi siempre, son refritos de los clásicos métodos de reclutamiento.

Pero también existen los que se sitúan en el presente en una actitud positiva e intentan adelantarse a preparar y construir el futuro, sin amedrentarse ante el salto en el vacío que a veces suponen los cambios. Estos son los que optan por una ecología vocacional. Algunos "nuevos movimientos" han intuido algo de esto, ya que incluyen en sus filas, de una manera u otra, a laicos, consagrados o no, matrimonios, religiosos activos y contemplativos, etc.

La propuesta "ecológica" supone la "inclusión" de todos los carismas y vocaciones en la misión evangelizadora de la Iglesia. Cada uno tiene una funcionalidad específica, una forma característica de evangelización. Todos juntos pero no revueltos. 


\section{4.- La nueva propuesta de la pastoral juvenial latinoamericana}

Sin ánimos rupturistas y como fruto de un proceso de madurez teológica y pastoral, la pastoral juvenil latinoamericana hace una propuesta que considero muy válida, aunque no sea la única, entre tantos ensayos como se vienen haciendo. Todos sabemos que las nuevas propuestas pastorales no suponen necesariamente la desaparición de las ya existentes.

Esta propuesta tiene como base una nueva autocomprensión de la Iglesia:

- Comunión de comunidades, toda ella ministerial, donde todos tienen una igual dignidad que da el Bautismo. El Congreso Vocacional Brasileño (2003) tuvo como lema "El Bautismo fuente de todas las vocaciones".

- En la Iglesia todos son protagonistas de la evangelización, y no sólo objeto de evangelización. Los laicos no son, como antes, el brazo largo de la jerarquía, sino que tienen una "vocación específica", porque tienen su forma propia de evangelizar, diferente a la de los sacerdotes y religiosos, pero igualmente necesaria para la construcción del Reino.

- El sacerdocio común de los fieles y el ministerial, se ordenan el uno al otro, sin que supongamos preeminencia de ninguno de los dos.

- Cada uno, desde su vocación, su carisma, su ministerio, se convierte en signo para los demás (eco-sistema). Todos comparten la única misión de la Iglesia, todos son evangelizadores.

- La llamada radicalidad evangélica se presenta como característica bautismal que se puede vivir en cada una de las vocaciones cristianas. De hecho se impone una revisión de los textos escriturísticos vocacionales, que aplicamos reductivamente a las vocaciones religiosas o ministeriales y que se refieren, en casi todos los casos, a los seguidores de Jesús, en cualquiera de las vocaciones.

Todos estos presupuestos teológicos son los que exigen el "salto cualitativo" del que habla del documento "Nuevas vocaciones para una nueva Europa". 


\section{5.- Opciones pedagógicas para la madurez en la fe y la opción vocacional}

En la PJ latinomericana se ha hecho la opción por desencadenar un proceso comunitario de formación que quiere partir de la fe, para llegar a la madurez de la fe, cultivando al mismo tiempo cinco dimensiones formativas.

La PJ sueña con una Iglesia que:

A) Promueva el encuentro personal y comunitario con Jesucristo que nos envía a ser anunciadores de la Buena Nueva.

B) Una Iglesia coherente y testimonial que anuncie el evangelio con hechos y palabras.

C) Encarnada en la realidad, que escuche y responda a los gritos y necesidades de nuestros pueblos, solidarizándose con sus luchas, denunciando lo que no dignifica a los hombres.

D) Al servicio de la promoción de la dignidad humana y del proceso de liberación histórica de los pueblos.

E) Una iglesia que acoge a los jóvenes, los valora y los ama. Reconoce el protagonismo juvenil y su fuerza militante. Respeta sus diferencias.

F) Una Iglesia de comunión y participación donde los pastores dialogan y confían en los jóvenes, favorecen el protagonismo juvenil, desde, con y para los jóvenes.

G) Una Iglesia comunidad de comunidades, que da prioridad a la formación de pequeñas comunidades en los ambientes culturales y específicos de los jóvenes, acompañándolos en la elaboración de un proyecto de felicidad.

H) Que trabajando con instituciones de la sociedad civil, irrumpe como profeta en las estructuras sociales y económicas, políticas y culturales, para transformarlas.

Festiva. Que celebra el acontecer de Dios en la vida, en la realización personal y en los proyectos sociales, a través de la Oración, la escucha de la Palabra y la vivencia de la Eucaristía.

\section{Desafíos}

A) Ser una Iglesia profética, no tanto por las denuncias, cuanto por el anuncio vigoroso de la comunión y participación, en la unidad y en la diversidad. 
B) Una Iglesia con presencia maternal entre los jóvenes, especialmente con los excluidos, que aprende a tener espacios de comunión y participación.

C) Que practica la pedagogía incluyente del Evangelio, servidora de la sociedad, en tareas de reconciliación anunciando la justicia, la verdad y el amor.

\section{Soñamos con una PJ que:}

A) Fomenta, vive y asume las opciones pedagógicas latinoamericanas, organizada y sistematizada en sus procesos.

B) Generadora de procesos de educación en la fe, formación integral que los acompañe hacia la militancia; que concrete un proyecto de vida que incluya la participación ciudadana: social, política, cultural y eclesial.

C) Articulada, orgánica y planificada, en la que, al participar en la coordinación y organización, los jóvenes vayan madurando en la corresponsabilidad y servicio, de comunión y participación, para una mejor evangelización del mundo juvenil.

D) Una PJ misionera que evangeliza los ambientes específicos donde se desarrollan los jóvenes y pasan la mayor parte de su tiempo.

\section{Desafíos}

A) Si se continúa con un PJ que sale al encuentro de los jóvenes considerando sus intereses, búsquedas, etc. y propone a Jesucristo como sentido y respuesta de su vida, se contribuirá a su desarrollo integral, a la concreción de su proyecto de vida y a su compromiso por transformar la realidad en que viven.

B) Si se continúa con una PJ que tenga objetivos y propuestas claras, que lleve a acciones coherentes, concretas, eficaces, que garantiza la adhesión y el seguimiento de Jesús, se contará con formas adecuadas de evangelización.

C) Si se sigue con la opción preferencial por los jóvenes pobres, dándoles espacios de participación y formación, respetando su diversidad, podemos garantizar el protagonismo juvenil en la Iglesia.

D) Si la PJ no propone un Proyecto de vida que se concreta en un compromiso social, político, económico, eclesial, cultural, no habrá 
jóvenes felices que intervengan en la construcción de un orden social más justo y del Reino de Dios.

E) Si la PJ no involucra a la familia como primera educadora y transmisora de valores, no podrá brindar una formación adecuada a los jóvenes.

F) Si la PJ continúa con una espiritualidad encarnada fundamentada en el encuentro personal y comunitario con Dios, se tendrá una espiritualidad que une fe y vida y lleva a un compromiso transformador.

G) Si la organización de la PJ no favorece experiencias y espacios para la iniciación de los jóvenes en compromisos evangelizadores y solidarios ellos no podrán madurar sus inquietudes vocacionales de servicio.

\section{6.- El proyecto de vida como proceso}

En esta última etapa de reflexión de la PJ en América Latina, el proyecto de vida se ve como el instrumento pastoral a través del cual se puede llegar a realizar este sueño de una Iglesia al servicio del Reino y de unos cristianos que lleguen a una opción vocacional dentro de ella con madurez. Así lo vocacional no queda en un aspecto de la PJ, sino que se convierte en la vocación de la PJ.

\section{Planificando el proceso vocacional}

Se busca una PJ que acompañe a los jóvenes en su proceso personal y grupal de crecimiento, en el descubrimiento de su vocación, en el discernimiento y realización de su proyecto de vida y en la concreción de su compromiso militante.

A lo largo del proceso de formación personal y comunitaria se promueve el crecimiento y la maduración en estas cinco dimensiones:

1. Dimensión psicoafectiva: ser, poseerse, donarse en el amor.

2. Dimensión social y cultural: convivir, comunicarse.

3. Dimensión Política: Situarse, comprometerse históricamente.

4. Dimensión mística o teologal: Trascenderse

5. Dimensión técnica - Metodológica: Hacer - construir. 
Son las cinco dimensiones de la formación integral que es la primera opción pedagógica de la PJ.

\section{1.- Dimensión psicoafectiva}

Es una constante búsqueda de respuestas a la pregunta ¿Quién soy yo?

Incluye:

1. El autoconocimiento: mis intereses, valores, aspiraciones, historia, derecho, valores, sentimientos, limitaciones y defectos.

2. Autocrítica: revisión personal y búsqueda de superación. Coherencia de vida.

3. Autovaloración: Descubrimiento de la dignidad personal, autoestima y actuación como sujeto libre.

4. Autorrealización: sentirse amado y capaz de amar; ternura y jovialidad; saberse constructor de su propio futuro - Opción vocacional y profesional.

\section{2.- Integración socio-cultural}

La dimensión psicosocial supone descubrir al otro, al hermano. La cohesión grupal y la experiencia de vida comunitaria. Supone vencer los bloqueos de comunicación, conocimiento y afecto por el otro. Cooperación y comunión.

Supone asumir los aspectos positivos de la propia cultura, tener identidad social.

\section{3.- Dimensión política}

Corresponde a la dimensión política buscar y responder a las preguntas “¿Donde estoy? Y ¿Qué hago aquí?”. Se quiere formar a los jóvenes para la acción socio-política y el cambio de estructuras.

Pasos que han de darse:

\section{Sensibilización}

De adolescente se tiene una conciencia ingenua y deformada, encerrada en el mundo de sus conflictos personales. El joven percibe los problemas sociales y toma actitudes de compasión y solidaridad. 
No hay que desperdiciar esta etapa que ha de superarse progresivamente.

\section{Concientización}

De la compasión y de las pequeñas acciones llevarlos al descubrimiento de las causas estructurales y a la realización de acciones más transformadoras. La conciencia crítica debe partir de las necesidades sentidas, de la realidad percibida y de las acciones realizadas.

\section{Organización - Movilización}

Comienza por la participación en movimientos populares y termia en el compromiso de acción organizada del pueblo para la transformación de la sociedad. La creación de organizaciones.

\section{4.- Dimensión mística o teologal}

Es un proceso de educación en la fe. Responde a la sed de Dios y a la pregunta ¿Para qué existo?

Consiste en ayudar al joven a asumir a Dios como el absoluto de su vida personal y de la historia. En el caso de la Pastoral juvenil comprende:

- Crear las condiciones para la acogida del mensaje salvador. Tomar conciencia de la necesidad de salvación personal y social. Desmitificar las falsas imágenes de Dios y de la Iglesia.

- El anuncio de Jesucristo mediante una catequesis adecuada. Debe llevar a una primera conversión que se manifiesta en el cambio de mentalidad y de vida. En la adhesión a Cristo liberador y su Reino y en la conciencia de ser Iglesia.

Se trata de profundizar, manifestar y celebrar comunitariamente la primera conversión de manera más madura y participativa. Manifiesta que es Iglesia en tres campos:

Catequético: profundizando en el Misterio de Cristo y su Iglesia para dar razón de su fe.

Litúrgico: Celebrando con su pueblo los momentos litúrgicos fuertes, especialmente en los sacramentos, que va relacionando con su vida.

Profético: Confrontando la vida personal y social con el Evangelio; asumiendo el anuncio y la denuncia proféticos y la acción solidaria con los pobres. La fe se hace mística cuando se concreta en un compromiso de vida. 
Como fruto de una actitud de búsqueda de la voluntad del Padre, al estilo de Jesús. Supone recordar el camino recorrido como Éxodo y Pascua y un proceso de discernimiento vocacional. Ese compromiso será vivenciado en la vida Laical, Religiosa o en el Ministerio Ordenado.

\section{5.- Capacitación técnica}

Intenta responder a la pregunta “CCómo hacer?”. Gran parte de las dificultades de los animadores de grupos y de las organizaciones populares tienen su origen en la falta de capacitación de sus agentes en la definición y coordinación de sus estrategias de acción. Entendemos por capacitación técnica: De los grupos de iniciación, de los coordinadores, asesores y militantes en la planificación, ejecución y revisión de la acción. Capacitación Técnica en vista de un proyecto político en función de la transformación de la realidad y la construcción de una nueva sociedad. Líderes para la militancia en los movimientos y organizaciones de transformación social, con una práctica democrática y participativa. Capacitación técnica en vista de un proyecto de Pastoral Juvenil. Capacitación de animadores y asesores para la militancia interna, garantizando la eficacia y la continuidad de los procesos pastorales.

Tiene su inicio desde el ingreso al grupo, y continúa en la práctica en el grupo de la dinámica acción reflexión, actividades formativas complementarias y en la acción de la comunidad.

1. Participación: Los jóvenes llegan al grupo sin ninguna experiencia de participación y con dificultad de comunicación. El primer momento será de recuperar la palabra y aprender a vivir en grupo, participar, trabajar en conjunto. Exige de los animadores crear ambiente favorable y técnicas adecuadas.

2. Acción - Coordinación. De asumir pequeñas tareas, el joven pasará a ser capaz de liderar acciones y coordinar actividades.

3. Planificación - Organización: ser capaz de organizar la acción grupal y contribuir eficazmente a la organización de la comunidad y de la sociedad, de modo democrático y participativo.

Esta es la tarea de los asesores, planificar y acompañar el proceso respetando etapas e integrando las cinco dimensiones. Estas dimen- 
siones no ocurren en tiempos sucesivos o etapas marcadas, sino que se dan las cinco al mismo tiempo, en todas las etapas, en todas las reuniones. Son sincrónicas, no diacrónicas.

\section{7.- El grupo o la comunidad juvenil}

\section{Segunda opción pedagógica de la PJ}

Los grupos pueden crearse en los diversos "ambientes" o "medios" donde los jóvenes viven sus diversos intereses. La adolescencia tiene un deseo enorme de liberarse de la familia, encontrar autonomía y empezar a construir sus proyectos. En el grupo se construyen relaciones con los iguales y se establece la propia identidad.

\section{Qué es un grupo}

El grupo tiene un objetivo común, pero cada participante tiene su identidad, su pensamiento, su opinión. Pero va interiorizando al otro dentro de sí.

La familia es nuestro grupo primario, y a lo largo de la vida vamos construyendo grupos secundarios. El grupo o comunidad juvenil es uno de los fundamentales. El grupo es, como dice el P. Tonelli (Profesor de Pastoral Juvenil en la Pontificia Universidad Salesiana de Roma), como un nuevo vientre materno en el que se va gestando la nueva identidad del joven. En él se le devuelve la palabra, se entrena en el liderazgo, va creciendo en todas las dimensiones arriba explicadas y lo prepara para la inserción protagónica en la sociedad y en la Iglesia.

\section{Características de un Grupo}

1. No es la suma de individuos. Es una nueva entidad con leyes y mecanismos propios.

2. Los integrantes están reunidos en torno a una tarea común.

3. El tamaño de un grupo debe permitir la comunicación visual, auditiva y conceptual.

4. Tan importante es que el grupo esté al servicio del individuo, como viceversa. 
5. Aunque cada grupo tiene una identidad genuina, es indispensable que queden claras las identidades de cada uno.

6. Existen dos fuerzas contradictorias, una de cohesión y otra de desintegración.

7. Existe una interacción afectiva que asume diversas formas

\section{Los tres momentos de un grupo}

1. De la toma de conciencia, donde las dificultades son vistas de forma transitoria. Es el momento de la sensibilización.

2. Del diagnóstico, donde se descubren las causas que influyen en el funcionamiento del grupo. Se pierde la conciencia ingenua y aparece la conciencia crítica.

3. De la actuación, que tiene claros los objetivos y toma postura frente a las diversas situaciones.

\section{Evangelizar en grupo}

Así lo hizo Jesús, creó el grupo de Los 12. Los que llevaban una

"forma de vida apostólica". En PJ no hay verdadero grupo si no está vinculado con algún conjunto orgánico de la Iglesia. Se necesitan vínculos visibles. Esta vinculación orgánica permite a los participantes del grupo abrirse a la universalidad de la Iglesia.

\section{Proceso Grupal}

El proceso de crecimiento del grupo tiene tres etapas: Convocatoria, nucleamiento, iniciación apostólica como militantes en la Iglesia y en la sociedad. No vamos a entretenernos en describirlas.

\section{8.- Otra opción pedagógica: Acompañamiento y Asesoría}

La asesoría es el ministerio de acompañar, en nombre de la Iglesia, los procesos de educación de la fe en los jóvenes. El asesor provoca para crecer. Una de las herramientas es la revisión de vida y la revisión práctica. Su tarea principal es la planificación. 


\section{A) La planificación de los procesos en la fe:}

\section{Un camino de discermimiento vocacional}

Para llegar a un discernimiento vocacional es necesaria una actitud de planificación, con pasos previstos. La acción espontánea dificulta la concreción de objetivos.

En la planificación hay que formularse estas preguntas:

- ¿Qué metas queremos alcanzar?

- ¿Qué estrategias? ¿Qué pasos se deben dar?

- ¿Qué personas y equipos se deben involucrar?

La vocacionalidad y el proyecto se van construyendo. El proceso de maduración supone etapas. Estas etapas o momentos necesitan de una comprensión dinámica, y de una descripción clara de las utopías y de las imágenes que tenemos de "persona", "Iglesia" y "sociedad".

Ir al encuentro de los jóvenes y dejarse interpelar por ellos

No acercarse a los jóvenes para perpetuar nuestra institución: novicios, seminaristas... Se trata de una invitación para vivir la gratuidad, escuchando sus dolores, sus preocupaciones. Despojarnos de nuestros prejuicios para una mejor comprensión de la realidad. Como Cristo.

Conocer la realidad de los jóvenes

¿Quiénes son los jóvenes? ¿Cuáles son sus necesidades? ¿Cuáles son las tendencias de la realidad social que les afectan? ¿Qué grupos de jóvenes existen? ¿A cuantos jóvenes llegan estos grupos? ¿Qué actividades desarrollan estos grupos?

\section{Convocar para vivir el camino}

A) La convocatoria es la dinámica que garantiza la vida renovada entre los jóvenes. Supone: motivación, información, formación y propuestas apropiadas a su realidad (arte, deporte) suponen actividades cortas y masivas.

Estas formas de convocatoria hay que realizarlas de forma orgánica y convergente hasta llegar a la madurez en la fe. "Que los jóvenes evangelicen a los jóvenes". Es la dimensión misionera de la PJ. 
Se pueden organizar misiones juveniles en los ambientes donde están los jóvenes.

B) La nucleación es el tiempo indicado para la planificación y creación de los grupos. El grupo es una de las políticas educativas más importantes.

El grupo es sano cuando facilita estas experiencias:

1. Relación e intercambio interpersonal.

2. Formación y capacitación.

3. Organización y planificación.

4. Proyección social en el servicio ciudadano y evangelizador.

5. La celebración y la fiesta.

Esto responde a las necesidades de maduración de:

1. El propio mundo psicoafectivo.

2. La comprensión de la realidad.

3. La necesidad de estabilidad.

4. La capacidad oblativa.

5. La dimensión lúdica y del cuidado de la vida del planeta.

Las celebraciones son muy importantes (Aniversario del grupo)

\section{B) Planificando la madurez para la fraternidad}

Cada grupo tiene su historia: En un principio trabaja las relaciones interpersonales y está centrado en ellos mismos. Trabajan la capacidad de escuchar y hablar. Experimentan a Jesús como amigo.

Más tarde ya va incluyendo a los otros grupos que existen en la comunidad local y en la Iglesia. La formación en la acción es clave para hacerse nuevas preguntas. Las diferentes opiniones son causa de conflictos.

Cada vez se van identificando más con la persona de Jesús. Se aprende a resolver los conflictos. Como Jesús van aprendiendo a ponerse al servicio de los otros con gestos de solidaridad, compañerismo, amistad... Realizará actividades solidarias.

Ante estas nuevas responsabilidades frente a la sociedad muchos abandonan el grupo porque se sienten impotentes y frágiles. Es importante evaluar las acciones y revisar la vida para que se conviertan en experiencia de Dios.

En esta etapa de la vida comunitaria los jóvenes se hacen preguntas como estas: 
- ¿Qué hago? ¿Cuáles son mis valores? ¿Qué sentido tiene mi vida? ¿En qué puedo participar? ¿Qué puedo hacer?

\section{C) Iniciación a la militancia}

\section{Planificando la madurez para la misión}

Las preguntas anteriores llevan hacia un compromiso para la misión.

Se plantean nuevas preguntas ante las estructuras para responder a esa realidad a partir de la persona, la familia, el trabajo, la sociedad. La respuesta se da desde el discernimiento vocacional. Es la etapa de iniciarlos en la militancia y en la opción vocacional.

Concreción del proyecto de vida

En el encuentro Latinoamericano de Quito del 2003 se definió como "un compromiso personal de los que realizaron un proceso de educación en la fe, en grupo o en otras instancias de la Pastoral Juvenil, en la transformación del ambiente donde viven, a partir del testimonio y de actitudes frente a las estructuras de muerte que limitan nuestra sociedad latinoamericana."

La militancia es un proceso, pero también el punto de llegada de este proceso, organizando y sistematizando el proyecto de vida que ayuda con mayor claridad y decisión a intervenir en el mundo.

Es un estilo de vida que expresa la presencia de Jesús en sus palabras y actos. Supone:

\section{Estilo de vida del militante}

- Pertenecer a un grupo. Experiencia de Iglesia.

- Tener conciencia crítica.

- Ser protagonista, capaz de diálogo y comunicación.

- Saber administrar los conflictos, respetar lo valores y visiones de otras personas.

- Realizar una acción reflexionada, contextualizada y organizada.

- Entregar su vida con espíritu de gratuidad.

- Estar consciente de las otras culturas y respetarlas. 


\section{Militancia: exigencias en el acompañamiento}

Reclama la presencia de alguien que le anime y ayude a procurar soluciones y respuestas para las preguntas que, como nunca, hierven dentro del joven. Lo pueden acompañar su grupo de referencia y personas que le ayuden en la búsqueda de felicidad, coherencia y compromiso.

\section{Militancia: exigencias de la formación}

Así como es tiempo de mucha actividad, es un tiempo de mucha formación.

Los jóvenes están trabajando en diferentes ámbitos de las organizaciones sociales y, algunos, en partidos políticos o instancias gubernamentales. Hay que romper con la desconfianza de que los jóvenes no están preparados.

\section{Desafíos de la militancia a la PJ}

Esta última etapa de la PJ está requiriendo a la PJ itinerarios formativos que faciliten la continuidad de las experiencias comunitarias con jóvenes mayores. Creación de grupos de vida para continuar la formación pastoral en la integración de fe-cultura-vida. Nuevas formas de evangelización con respecto a la ciudadanía y seguimiento de Cristo, con una espiritualidad liberadora y una metodología de participación e implicación de agentes. Reconocimiento de los nuevos desafíos que los jóvenes militantes encuentran en su condición de jóvenes adultos. Procesos educativos con la dimensión de compromiso social y político.

\section{Militancia: exigencias en el acompañamiento}

Un acompañamiento integral, que abarque la teología, la política, la sociología, la dirección espiritual, la planificación...

Faltan personas que escuchen, animen, cuestionen y lo hagan mezclando afecto y competencia.

\section{Se imponen}

Espacios comunitarios donde vivir la militancia. Como las primeras comunidades cristianas. Que el que acompañe tenga su propia experiencia de militancia. Que el militante sea acompañado en su pro- 
ceso por la comunidad cristiana, relacionados con la jerarquía. Ubicar su compromiso en referencia con su vocación. El acompañamiento calificado de un asesor que le ayude a encaminar los conflictos, ser amigo y testimoniar su fe.

Estar dispuesto a generar otro tipo de redes para otros mares, articulando a los militantes del sector político, social, cultural.

\section{Militancia: exigencias de organización}

La militancia es un "estado de vida" individual, pero comunitario. El desafío es una organización de militantes. También integrarse en los organismos de la Pastoral de conjunto. Para un trabajo en red: encuentro de la diversidad.

\section{Función de la red}

Compartir experiencias. Profundizar en la espiritualidad y en la mística. Desarrollar acciones conjuntas y agendas comunes. Repensar la militancia desde una realidad cambiante.

El seguimiento de Jesús nace del encuentro personal con el Resucitado, que nos desafía a ir mar adentro. Se trata de vivir lanzados en la profundidad del discernimiento que nace de una opción fundamental por el Reino.

\section{Proceso}

El proyecto de vida personal es un camino de opciones progresivas y de discernimiento permanente. Dios nos habla en su palabra, en nuestra vida, en los demás, en los acontecimientos históricos y sociales, en nuestra práctica pastoral.

\section{Una necesidad vital}

El proyecto de vida es una invitación a tomar la vida en nuestras manos. La ausencia de un proyecto de vida nos enfrenta a la dolorosa realidad de la pérdida de identidad y a la falta de perspectivas de futuro, a la incapacidad de soñar.

\section{La vida como misión}

El proyecto personal de vida es un camino que nos ayuda a asumir y a definir nuestra vocación para seguir a Jesús, haciendo nuestra 
su misión a través de un compromiso transformador de la realidad, como miembros de una comunidad de fe.

\section{Puebla: camino vocacional( P.854)}

El documento de Puebla (en este año se cumplen sus bodas de plata) propone un itinerario vocacional que puede servirnos como punto de referencia.

Todos los cristianos debemos realizarnos:

1. Como hombres-mujeres.

2. Como cristianos.

3. Descubrir la vocación concreta (laico, consagrado, ministro...)

De este modo cumpliremos plena y orgánicamente, nuestra misión evangelizadora.

\section{Dar vida a la vida}

El proyecto de vida es la orientación organizada de los esfuerzo por dar vida a la vida. Consiste en tomar conciencia de la realidad, buscar la verdad, reflexionar la vida, elaborar la experiencia, crear orden y belleza, meditar, contemplar.

\section{Fundamentación teológica}

Dios tiene un proyecto de amor de Padre que camina con su pueblo, del Hijo que se hace camino, verdad y vida; y del Espíritu por el que no faltan las aguas que revigoricen a todos los que descubrieron que la vida es caminar.

Jesucristo es la encarnación del Proyecto de Dios para el ser humano. Un proyecto de salvación y realización plena. Que todos sean felices, libres y gratuitos. Hacer la voluntad del Padre. Anunciar y realizar el Reino de Dios Padre. Para ello reunió al grupo de los 12.

\section{El proyecto de Jesús invita al seguimiento}

Para los jóvenes es maravilloso porque trae consigo el deseo de vivir en plenitud, porque conlleva la voluntad de aceptarse y ser aceptado gratuitamente, nos hace sentirnos útiles y felices. La diferencia entre las personas se da en la calidad de su proyecto de vida, de su vocación. 
Revisión de vida y revisión de práctica

Es un método para construir personalidades definidas, con vocación de cristianos comprometidos con la realidad y con el Reino. (Civilización del amor, tarea y esperanza).

\section{9.- Pasos para elaborar el Proyecto de vida. Los tres momentos:}

\section{Primer momento}

Suscitar inquietudes por el sentido de la vida. Haciendo que aflore lo positivo de cada joven. Que el joven tome conciencia de su propia búsqueda.

Dar los primeros pasos prácticos, a modo de ensayo, que le sirven al joven para comenzar a considerar la necesidad de un proyecto estable de vida.

\section{Segundo momento}

En esta fase vamos al encuentro de las motivaciones por el sentido de la vida. Hay motivos internos y motivos sociales. Es el momento para proponer la elaboración de un proyecto de vida.

\section{Tercer momento}

Se desarrolla cuando los primeros esbozos del Proyecto de vida se confrontan en las experiencias grupales y en el desarrollo cotidiano. En esta fase vamos al encuentro de decisiones vocacionales en que la persona se va orientando hacia un campo específico de la evangelización en la Iglesia.

\section{Elaboración del proyecto}

El diseño puede corresponder a estas preguntas:

- ¿Dónde estoy? ¿Cómo estoy?

- ¿a dónde quiero ir?

- ¿Cuáles son los recursos con los que cuento?

- ¿Cómo voy alcanzando las metas? 


\section{Propuesta concreta}

Primero: el proyecto es también una planificación pastoral definida por:

- Mi situación de vida

- Mi historia

- Lo que creo

- El diagnóstico personal dce realidad y de práctica

- Mi compromiso pastoral y social.

La segunda propuesta tiene un carácter de estudio y de orientación. Significa profundizar en:

1. Mi persona, lo que soy

2. Mi esperanza: la sociedad que quiero

3. Mi credo: las certezas de mi vida

4. La misión que me toca: ser Iglesia en el mundo.

5. Mi camino: elaboración de mi proyecto. 


\section{ANEXO}

Presentamos los dos guiones que en el libro: "Proyecto de vida: camino vocacional de la Pastoral Juvenil" (Celam No 162), nos ofrece de la pag, 118 a la 140.

\section{Proyecto de vida: Camino Vocacional de la PJ}

Propuestas concretas para elaborar el proyecto de vida

Presentamos, a continuación, a modo de apoyo técnico, dos esquemas posibles para la elaboración del Proyecto de Vida.

Son dos propuestas concretas. La primera propuesta está muy próxima a la planeación pastoral. El proyecto de vida no deja de ser, también, un proyecto pastoral. Esta propuesta tiene, pues, más semejanza con la elaboración de un "Marco Referencial" porque todo proyecto de vida es, de alguna forma, un marco de referencia. Los cinco pasos que la definen son:

- mi situación de vida (marco situacional);

- mi historia (marco histórico);

- lo que creo (marco doctrinal);

- el diagnóstico personal de realidad y de práctica; y, finalmente;

- mi compromiso pastoral y social (marco operativo), con sus iniciativas a corto, mediano y largo plazo, en una perspectiva integral.

La segunda propuesta tiene un carácter de estudio y de orientación. Es una propuesta más extensa y presenta una sugerencia de profundización en cada uno de sus cinco pasos:

- mi persona: lo que soy;

- mi esperanza: la sociedad que quiero;

- mi credo: las certezas de mi vida;

- la misión que me toca: ser Iglesia en el mundo; y, finalmente;

- mi camino: elaborando mi Proyecto. 
Propuesta 1: proyecto de vida: "Un instrumento para planificar la vida"

Mi situación de vida (marco situacional)

Jesús miró hacia atrás y vio que lo seguían.

Ellos le preguntaron: "Maestro, ¿dónde vives?".

Jesús les respondió: "Vengan y lo verán". (Jn 1,38-39)

Es importante describir la realidad donde vivimos y desarrollamos nuestra acción:

- ¿Cómo anda mi vida aquí, en el lugar donde vivo? (Trabajo profesional trabajo pastoral, barrio, municipio, provincia, estado, país...).

- ¿Cuáles son los principales acontecimientos de mi vida: familiar, comunitaria, profesional escolar, afectiva, pastoral...?

- ¿Cuáles son mis compromisos? ¿Cómo los hago? ¿Cómo me siento en esa experiencia?

Yo tengo una historia (marco histórico)

Desde el seno de tu madre,

Yo te escogí. Tú eres mío. (Sal 139)

Es importante mirar (contemplar) el camino recorrido para identificar las elecciones hechas y para poder vislumbrar los influjos recibidos de la familia, de la escuela, del grupo, de las personas. Es necesario retomar esas vivencias en perspectiva personal, asumiendo, cada uno/a, su historia y su vida.

- ¿En qué modo ha influido en mi vida los acontecimientos de mi pasado, de mi propia historia?

- ¿Cuáles son las elecciones que siento mías y cuáles siento que son resultado del influjo de los demás en mi?

- ¿Qué historia quiero construir con mi vida?

- ¿Qué aportes quiero ofrecer en la historia? 


\section{Lo que creo (marco doctrinal)}

Mi testimonio es válido, porque sé de dónde vengo y hacia dónde voy. (Jn 5,31)

Es importante tener la certeza del para qué y el por qué de nuestra vida.

- ¿Quién es Jesús para mí?

- ¿Qué es el Reino de Dios para mí?

- ¿Cómo debe ser la nueva persona humana?

- ¿Cuál es mi proyecto de nueva sociedad? (En los aspectos político, social, económico, cultural.).

- ¿Cuál es la Iglesia en la que quiero vivir mi misión?

- ¿Cuáles son los elementos fundamentales de la Pedagogía que quiero vivir en la familia, en la comunidad, en mi trabajo?

Nuestras creencias no son únicamente teológicas. Son también pedagógicas, políticas, sociales. La afirmación de estos aspectos es importante tenerlos en cuenta.

\section{¿A cuál distancia estoy del ideal? \\ (Diagnóstico personal).}

El Espíritu del Señor me consagró

para llevar la Buena Nueva a los pobres,

a los cautivos la liberación,

y proclamar un año de gracia del Señor. (Lc 4,16-21)

Es importante medir las fuerzas y los recursos, los límites y los errores.

- Mirando lo que fui escribiendo, ¿dónde voy concentrando mis energías?

- ¿Cuáles son mis mayores dificultades, límites?

- ¿Cuáles son mis mayores logros, avances?

- De las necesidades que voy descubriendo, ¿cuáles voy a asumir como prioridad para enfrentar e intentar resolver?

- ¿Con qué recursos o fuerzas cuento para lograrlo? 
Se trata de elaborar un diagnóstico de mi realidad y de mi práctica. Voy descubriendo cualidades y fragilidades que deben ser trabajadas, haciendo que el proceso sea realmente un proceso de elaboración, de vivencia y de perspectivas siempre más coherentes.

\section{Mi compromiso pastoral y social (marco operativo)}

\section{Todos eran unidos, vendían lo que tenían y} compartían todo en común. (Hch 2,44-46).

Realizado el diagnóstico, es necesario definir dónde centrar las fuerzas, reconociendo qué es aquello que necesita ser realizado, concretamente, para mejorar la situación descubierta. Teniendo en cuenta los principios orientadores que hemos conseguido definir, llegamos al momento del "Marco Operativo", al momento de elaborar estrategias que respondan a mis sueños, partiendo de la realidad concreta.

- ¿Qué acciones especiales se van imponiendo en el discernimiento que estoy haciendo? Las enumero de acuerdo a la "urgencia", priorizando las mismas en cada aspecto o área de mi vida: la familia, la escuela, la universidad, el trabajo, la afectividad, la comunidad, la pastoral, etc.; expresando la forma como las voy concretizar: ¿Qué?, ¿cuándo?, ¿cómo?, ¿con la ayuda de quién?

- ¿Qué acciones reflexivas (estudios, cursos, lecturas, participaciones...) voy a continuar realizando en mi vida personal, profesional y en mi compromiso pastoral, para profundizar en mis opciones y mi proyecto de vida?

- Con relación a mi acompañamiento: ¿Cómo voy a evaluar este Proyecto-de-Vida? ¿Cuándo? ¿En qué condiciones? ¿Con la ayuda de quién?

- ¿Qué lugar va ocupar el grupo/comunidad en la concreción de este proyecto?

- ¿Cómo voy a cultivar la dimensión teológica y teologal en lo cotidiano, asumido como propuesta de vida? (momentos de oración y de retiro, vivencia sacramental, celebraciones, lecturas, cursos,...).

- ¿Qué tiempo voy a dejar para mi descanso, recreación, afectos, amistades? Si es posible recuerdo y priorizo fechas, momentos, acontecimientos. 
Se trata de descubrir formas muy concretas de realizar, en la historia, el proyecto de vida. Las estrategias, tanto a corto plazo como a largo plazo, exigen tiempo, seriedad, apertura. Las "actividades" más indicadas aquéllas que son, al mismo tiempo, concretas, bien definidas y amplias. Habrá necesidad de adaptación. El riesgo está en la superficialidad en las decisiones.

Propuesta 2: elementos de estudio y de orientación para la elaboración del proyecto de vida.

La segunda propuesta se basa en la profundización de la fe de manera personal y grupal. Busca ofrecer elementos que ayuden en la elaboración del proyecto de vida, posibilitando una mayor vivencia eclesial en confrontación con el Proyecto de Jesús. Propone un esquema de estudio y orientación que pretende destacar y profundizar aspectos personales, sociales, cristológicos y eclesiales, como pilares para sustentar el proyecto de vida. Es un camino que puede ser hecho durante un proceso personal y de grupo o comunidad de vida.

\section{Mi persona: lo que soy.}

Por ser el punto de partida, hay varias sugerencias para que este aspecto penetre en la integralidad de lo que somos.

\section{a) Gestando mi autobiografía.}

Se trata de partir de lo más cercano: mi persona, mi vida, mi historia. Para realizarlo proponemos algunas cuestiones.

- Preparado el ambiente, si es un grupo el que realiza la experiencia, cada cual piense en el mejor modo de concentrarse para escribir su autobiografía, de la forma más completa posible.

- Inicia, por eso, tu camino con algunos datos biográficos: lugar de nacimiento, datos familiares, estudios, experiencias religiosas, etc.

- Recuerda los momentos más felices y los más tristes de tu vida; los momentos más significativos. 
- Habla de tu relación con tus padres, hermanos/hermanas, amigos/amigas, profesores/as, novio/novia, colegas de trabajo, compañeros las de comunidad, etc. ¿Cuáles son las personas que más han influenciado en tu vida?

- ¿Cuáles son para ti y cómo vives algunos de los valores fundamentales de la persona humana?

- Libertad: ¿Qué es para ti ser libre? ¿Te consideras libre? ¿Cómo? ¿Por qué?

- Sinceridad: ¿Te consideras sincero/a? ¿Por cuál razón?

- Responsabilidad: ¿Sabes asumir compromisos? ¿Otros deben recordártelos? ¿Sabes organizarte?

- Religiosidad: ¿Te consideras superficial o profundo/a? ¿Quién es Dios para ti? ¿Qué influencia tiene Dios en tu vida? ¿Qué espacio ocupa la oración en tu vida?

- Placer: ¿Te sientes satisfecho/a, completo/a, feliz con aquello que vives y haces?

b) Retornando la autobiografía.

Recuerda tu historia personal a partir del relato que realizaste en tu autobiografía y medita algunas preguntas:

- ¿Qué marcas/huellas tengo en mi vida?

- ¿Cuáles son los momentos más felices? ¿y los más tristes?

- Elige a una persona de tu grupo o comunidad con quien tengas afinidad y confianza y comparte con ellas los descubrimientos que realizaste, las marcas o huellas que fuiste reconociendo en el camino de tu vida.

- Comparte comunitariamente y con tu acompañante y, después, ve pensando: ¿Qué sentimientos he experimentado en esta vivencia?

c) Mis relaciones.

- Pinta o dibuja en una hoja de papel blanco tu "red", las relaciones que tienes y/o estableces con: tus padres, tus hermanos/as, amigos/as, profesores/as, novio/a, colegas de trabajo, etc.

- ¿Qué cuestionamientos y realidades te transmite tu dibujo?

- ¿Qué sensaciones te surgen? 
- Comparte con tu comunidad y con tu acompañante tus sentimientos y aprendizajes.

- ¿Cómo está tu relación con el "mundo", el" cosmos", la sociedad, la Iglesia, el otro?

d) Mis valores.

- Anota la historia de tus deseos más profundos y más significativos, desde el momento que puedas recordar... Escríbelos.

- Medita, después, las siguientes preguntas:

- ¿Alguna vez vuelven a ti esos deseos? ¿Siguen presentes con la misma fuerza del principio?

- ¿Fueron cambiando? ¿Cuándo? ¿A razón de qué?

- ¿Qué nuevos deseos y sueños fueron surgiendo en tu vida?

- Comparte con una persona de tu comunidad y con tu acompañante tus sueños y sentimientos más profundos.

\section{Mi esperanza: la sociedad que quiero.}

Una manera adecuada de ubicarnos en la sociedad es seguir un buen esquema de análisis de coyuntura, que nos ayude a tomar decisiones personales ante la realidad social que vivimos. Proponemos una forma de visualizar la sociedad, procurando detectar los principales acontecimientos, describir los escenarios que se presentan, ver los actores que se desenvuelven en dichos escenarios y describir las relaciones de fuerza que se van manifestando.

\section{a) Coyuntura y estructura 1}

En la construcción del Proyecto Personal de Vida existe la necesidad de que cada uno/a logre situarse: ¿Dónde vivo? ¿Cómo es la rea-

${ }^{1}$ Algunas definiciones: Coyuntura: momentos históricos específicos de una sociedad que dependen del modo como se combinan las propuestas, las intervenciones, las acciones, en fin, la voluntad política de los diferentes actores sociales, con las posibilidades ofrecidas por las respectivas bases objetivas de existencia.

Análisis de estructura: análisis de la historia viva, de la historia aconteciendo y teniendo en cuenta las estructuras y la historia pasadas. 
lidad en la que estoy inserto/a? ¿Cuáles son los cuestionamientos que me hace la realidad? ¿Cuáles son las principales características de la sociedad en la que vivo (en sus aspectos social, político, económico, cultural)? ¿Qué influencia tienen en mi propia vida?

Intentaremos, entonces, mirar los hechos de la realidad, analizando y buscando contextualizar y profundizar sus causas.

\section{b) Acontecimientos}

Son los hechos que adquieren un sentido especial para un país, para una clase social, un grupo social o una persona. Por ejemplo: un beso puede ser un hecho común, pero el beso de Judas es un acontecimiento.

Para el análisis de coyuntura, lo fundamental es analizar los acontecimientos y saber distinguirlos de los hechos, después jerarquizarlos de acuerdo a su importancia. Es decir que, al analizar la coyuntura no vamos a tomar cualquier acontecimiento, sino aquellos más significativos para nuestro análisis. Esta selección de acontecimientos no es neutra, revela siempre la percepción que una sociedad, grupo social, clase o persona tienen de la realidad y de sí mismos.

\section{c) Escenarios}

Los escenarios son determinados espacios donde se desenvuelven las acciones de la trama social y política. El escenario se puede transformar de acuerdo con el desarrollo de la lucha social y/o política. Por ejemplo, en un contexto electoral tenemos varios escenarios: las internas partidarias, el estado, las empresas, los partidos políticos, etc.

Cada uno de estos escenarios presenta sus particularidades. Éstas son las que influencian el desarrollo de la lucha. Muchas veces, el hecho de cambiar de escenario es una condición importante de la transformación del proceso. Es importante, pues, saber identificar los escenarios donde se desarrollan las luchas y las particularidades de los diferentes escenarios.

La visualización de los escenarios es la forma concreta como se logra leer la realidad en la cual vivimos, la región donde estamos, la pastoral en la que estamos metidos, la Iglesia que se presenta... Más 
que un ejercicio, es una manera de exigir de nosotros que tengamos una "postura social" más definida. Esto mismo es válido en el análisis de los actores y en la descripción de las relaciones de fuerza.

\section{d) Actores}

El actor es alguien que representa, que encarna un papel dentro de un conflicto, dentro de una trama de relaciones. Un individuo es un actor social cuando representa algo para la sociedad; cuando encarna una idea, una reivindicación, un proyecto, una denuncia. También pueden ser actores: una clase social, un grupo o institución social (sindicatos, partidos políticos, etc.), los medios de comunicación social, las ONGS, las Iglesias, etc.

\section{e) Relaciones de fuerza}

Las clases sociales, los grupos, los diferentes actores sociales están en relación unos con otros. Esas relaciones pueden ser de confrontación, de coexistencia, de colaboración, de parálisis, que estarán siempre revelando una relación de fuerza, de dominio, de igualdad, de subordinación.

Para poder reconocer las consecuencias concretas del análisis de la coyuntura es preciso percibir claramente la relación de fuerzas existentes en el objeto de análisis. Puede ser, por ejemplo, el capítulo de las clases sociales; del gobierno internacional, nacional y local; de la Iglesia amplia y local; de la Pastoral Juvenil general y local; incluso de la propia comunidad. Se trata de ubicarnos en un mundo que tiene ideologías, posiciones e intereses diferentes y descubrir qué se hace para conseguirlos o defenderlos.

A veces esa relación se revela a través de indicadores cuantitativos, es el caso de una elección: el número de votos indicará la relación de fuerzas entre partidos, grupos y clases sociales; otras veces necesitamos buscar formas para verificar la relación de fuerzas que son "menos visibles": ¿Cuál es la fuerza de un político o de un movimiento social? ¿Cómo medir aquello que no tiene registros cuantitativos?

Otra idea clave es que la relación de fuerzas no es inmutable, ella sufre transformaciones permanentemente, y es por eso que la política está tan llena de sorpresas. 
La coyuntura, por lo tanto, es un trozo de algo en movimiento, es un momento del proceso. Los acontecimientos, las acciones desarrolladas por los actores sociales, generando una situación que defina la coyuntura, no se da en el vacío. Tienen relación con el pasado, con la historia, con las relaciones sociales, económicas y políticas establecidas a lo largo de un proceso.

\section{f) Profundizando el tema de la coyuntura}

Hay dos modos de leer la coyuntura:

A partir de la situación o del punto de vista dominante.

A partir de la óptica de los movimientos populares; de las clases subordinadas, de la oposición del poder dominante.

La finalidad del análisis de coyuntura es reordenar los elementos de la realidad, la situación dominante para mantener el funcionamiento del sistema, del régimen.

El análisis hecho a partir del poder dominante o hegemónico tiene como finalidad percibir la correlación de fuerzas que existe. Eso exigirá una postura personal, consciente, en el conflicto. Estamos elaborando un proyecto de vida donde las creencias teológicas y sociológicas necesitan encontrar su coherencia en la vida.

Otros elementos que deben ser considerados para realizar un análisis de coyuntura:

Percibir el conjunto de fuerzas y problemas que están por detrás de los acontecimientos.

Procurar descubrir las señales que apuntan a "lo nuevo", lo no acontecido, lo inédito.

Ver el hilo conductor de los acontecimientos, es decir, descubrir e investigar las relaciones y encadenamientos, la lógica, las articulaciones, los sentidos comunes de los acontecimientos.

Escribir, aunque sintéticamente, la esperanza y la utopía social que nos dinamizan es muy importante. Estoy afirmando no solamente las esperanzas que me mueven, sino también las luchas concretas que consigo vislumbrar para definir el mundo que deseo construir. Es evidente que eso va madurando, pero hay principios orientadores que se volverán "marcos" en mis actitudes.

Nuestro concepto de la nueva sociedad tiene de fondo la afirmación de que el hombre y la mujer son capaces de oponer a las situa- 
ciones decepcionantes e injustas una fuerza contradictoria: la esperanza. Esperanza de que aquello que no es, puede ser y hacerse realidad. Por eso tenemos de base la convicción de que la nueva sociedad es un acontecimiento utópico que nos mueve a tener una imaginación creadora para tener en cuenta el futuro real, a partir de un presente capaz de ser transformado y mejorado. Asimismo esta convicción se enmarca en el acontecimiento del Reino de Dios, en el cual alimentamos la esperanza de una sociedad fraterna, de paz, armonía social, participación justa y equitativa de todos los bienes producidos por el trabajo de todos/as.

\section{Algunas pistas para la reflexión...}

- ¿Cuáles son las principales características del modelo de sociedad en el que vivimos?

- ¿Cuáles son sus consecuencias sociales, políticas y económicas para el pueblo, principalmente para los más débiles, pobres/empobrecidos?

- ¿Estas características se aproximan al sueño de la Nueva Sociedad que queremos?

- ¿Qué nuevos modelos de hombre y mujer queremos construir?

- ¿Qué principios reconozco y elijo como fundamentales para vivir y construir la nueva sociedad?

- ¿Qué actitudes necesito cultivar en mí para que la nueva sociedad sea posible?

- ¿Cuál es el sueño de sociedad que tengo? Procurar definirlo.

\section{Mi credo: las certezas de mi vida}

Todos vivimos un marco doctrinal básico. Se trata del fundamento trascendental: ¿Cuáles son las razones de mi vida? Queremos ayudar, de modo especial, a profundizar en la perspectiva cristocéntrica de nuestro proyecto de vida y, por eso, ofrecemos algunas sugerencias más fuertes en este aspecto. 


\section{a) El proyecto de Jesús}

Es necesario, en este momento, profundizar la propuesta de Jesús, partiendo del conocimiento de su realidad a través del contacto con la Palabra. Será necesario entonces percibir cuál era la realidad en la que Jesús estaba inserto económica, social, política, ideológica y culturalmente. Se trata de comprender el contexto histórico y la acción concreta de Jesús, percibir cuáles son las interpelaciones, las enseñanzas, las exigencias de transformación que el seguimiento de Jesús nos impone. Éste es el momento de la exégesis, de las interpretaciones, de las repercusiones de la Palabra en nuestra propia vida.

\section{b) Conocer a Jesús desde el Evangelio de Marcos.}

Proponemos realizar, como primer paso, una lectura de todo el Evangelio de Marcos (capítulos 1 a 16). El contacto inicial con el texto debe ser desarmado de pretensiones de interpretación o de responder a preguntas. El objetivo es solamente realizar una lectura corrida, para tener una visión global.

En un segundo momento proponemos realizar una nueva lectura del texto como producto histórico cultural, observando las puntualizaciones y aspectos: económico, social, político y cultural-ideológico. Se sugiere ir anotando las reflexiones y descubrimientos, para volver sobre ellos para profundizarlos y enriquecerlos.

\section{c) Algunas pistas para la interiorización y el análisis:}

Lo económico:

- ¿Cómo vivía el pueblo de Jesús? ¿Qué producía? ¿Cómo era el modo de producción?

- ¿Cuáles eran los medios de producción de aquel tiempo? ¿A quién pertenecían esos medios?

- ¿Cuáles son las profesiones que aparecen en el relato evangélico?

- ¿Cuál es el problema económico básico que aparece?

Lo social:

- ¿Cómo aparece la división de clases o de grupos sociales?

- ¿Cómo son las relaciones entre las personas (justas o injustas)?

- ¿Cómo aparecen las relaciones entre las clases y grupos sociales?

- ¿Cómo aparece el bienestar o malestar social?

- ¿Cuál es el problema social básico que aparece? 
Lo político: militares...)?

- ¿Cómo aparece el poder dentro de la sociedad civil (líderes, partidos, asociaciones...)?

- ¿Quién ejerce el poder? ¿Cómo es ejercido ese poder?

- ¿Cuál es el problema político básico que aparece?

Lo cultural-ideológico:

- ¿Quiénes son discriminados/marginados en el tiempo de Jesús? ¿Por qué son discriminados/excluidos?

- ¿Cuáles son las prácticas religiosas del pueblo?

- ¿Cómo aparece la influencia de la religión?

- ¿Qué significado tiene todo eso para mí?

\section{d) Jesús, un proyecto de amor encarnado}

La pregunta fundamental del Señor: "¿y tú quién dices que soy?" (Mt 16,15), se dirige permanentemente a la juventud. La verdad sobre Jesús necesita ser reconocida por los/as jóvenes cristianos/as y estar acompañada por el seguimiento y el compromiso con su Proyecto Liberador y con la construcción de la Civilización del Amor.

e) Conocer a Jesús desde la imagen que tenemos.

Te sugerimos recuperar la imagen de Jesús que vive en la memoria de nuestro pueblo. Que te acerques a diferentes personas y compartas y preguntes:

- ¿Quién es Jesús?

- ¿Qué dicen las personas sobre Él?

- ¿Qué historia cuenta la gente sobre Jesús?

- ¿En cuáles situaciones el pueblo recurre a Jesús?

- ¿Cuál es la imagen que tú tenías antes de Jesús?

- ¿Cuál es la imagen de Jesús que tienes en este momento?

\section{f) Conocer a Jesús revisitando el Evangelio con nuevas pregun-} tas

Te proponemos, ahora, realizar una nueva lectura del Evangelio de Marcos y que vayas respondiendo y analizando las siguientes cuestiones: 
- ¿Cómo se relaciona Jesús con los marginados y excluidos de su tiempo: mujeres, niños, enfermos (leprosos, hemorroisa...), extranjeros, publicanos, prostitutas, pecadores...?

- ¿Cuál es el llamado que Jesús hace a los pobres?

- ¿Cómo se revela la humanidad de Jesús, sus sentimientos?

- ¿Cómo se relaciona Jesús con el Padre?

- ¿Cómo se relacionaba Jesús con los poderosos de su época: fariseos, doctores de la ley, escribas, saduceos, autoridades (gobierno, religión.......?

- ¿Cuál es el llamado de Jesús a los ricos y poderosos?

- ¿Cómo se posicionan los poderosos con relación a Jesús?

- ¿Cuáles son las consecuencias de la acción y posiciones asumidas por Jesús y sus discípulos?

- ¿Cómo asumo yo, en mi vida, el Proyecto de Cristo? ¿Cómo me puedo comprometer de forma radical con la propuesta liberadora de Cristo?

- ¿Cómo puedo transparentar y traducir esa propuesta en mi Proyecto de Vida?

Jesucristo es el verbo Encarnado que revela el Misterio de Dios y de la propia persona. Jesús de Nazaret es el "Hombre Nuevo", diferente, perfecto. El hombre del modo que Dios siempre lo soñó. "Se hizo carne y habitó entre nosotros" (Jn 1,14).

Él no se apegó a su condición divina, se negó a sí mismo y asumió la condición de siervo, haciéndose semejante a los hombres (Flp. 2,7).

Siendo pobre, asume un proyecto de liberación de los/as marginados y excluidos, y consecuentemente, denuncia todo aquello que disminuye o amenaza la vida.

g) Apuntes para la profundización sobre Jesús y su vida

Jesús resumió su vida en torno a dos objetivos: reconciliar a toda la humanidad con el Padre y reunir a los hombres y mujeres en una comunidad de hermanos/as.

El primer objetivo: Reconciliar a toda la humanidad con el Padre. Jesús no se cansaba de hablar de su Padre, de nuestro Padre. En sus palabras y en sus acciones concretas con los simples, los pobres, los sufrientes, las mujeres, los niños y también con los poderosos, 
Jesús revela cómo es el Padre y cómo Él nos ama: "Quien me ve a mí, ve a mi Padre" (Jn. 12,45). Nos enseña también que la reconciliación con el Padre pasa necesariamente por la aceptación de Él: "Nadie va al Padre sino por mí" (Jn 14,6).

¿Por qué Jesús habla tanto de su Padre y nuestro Padre?

- Porque Él ama a su Padre: "Mi Padre y yo somos uno" (Jn 10,30).

- Para acercamos al Padre y dejamos reconciliar con Él.

- Porque ningún proyecto histórico que ignore o reniegue de la aceptación y la relación filial con el Padre es capaz de establecer relaciones de libertad, de justicia, de fraternidad y de igualdad entre los ciudadanos/as, sino por el contrario va a vivir desde la discrimin ción y la opresión.

El segundo objetivo: reunir a todos los hombres y mujeres en una sola familia, en un solo pueblo, en una sola comunidad de hermanos y amigos.

Ámense unos a otros como yo los amé (Jn 15,12).

Ya no hay judío ni pagano, esclavo ni hombre libre,

varón ni mujer, porque todos ustedes no son más

que uno en Cristo Jesús (Gal 3,28).

Jesucristo rescata la dimensión totalizante de la persona humana, superando la división dualista. Jesús consagra el valor de la persona humana y asume en su cuerpo la plenitud de la grandeza humana. Podemos constatar esto en los siguientes textos bíblicos: Mt. 12, 1- 8; o bien de que la persona está por encima de la ley: Mt 12,9-14; Mt 15,21- 28; Mt 15,29; Jn 1,36-39; Mt 25,31-46; Jn 8,1-11; Jn 4,5-26; Ef 4,22-24; Mt 9,11-13.

Jesús se lanza a la construcción de la unidad, no al nivel de los ricos y poderosos, sino uniéndose a los pobres y enfermos. Exigió que los ricos usaran sus bienes como expresión de amistad y amor a los necesitados. Planteó a los poderosos el ejercicio del poder como servicio.

Jesús concentró su vida, sus afectos, sus energías, en la realización de sus objetivos. Es realmente el mayor ideal de vida que alguien se puede proponer. Imaginemos cuánto habrá vibrado, con qué ardor habrá deseado que la humanidad viviese finalmente en paz, todos como amigos, iguales y hermanos de verdad. 
La Muerte y la Resurrección de Jesús son para nosotros esperanza y certeza de que el Reino vencerá a la injusticia y de que la Vida, y no la muerte, tiene la última palabra. La Resurrección de Jesús nos da la certeza de que Él continúa en la historia y de que la cruz no es el fin. Del encuentro permanente con el Resucitado en la Eucaristía, en la Palabra y en la Oración, en la Comunidad y en la Historia, nos viene la fuerza y la esperanza para seguir luchando y construyendo un mundo nuevo hasta que Él venga.

- ¿Cómo asumo estos dos objetivos de Jesús en mi vida?

- ¿Cómo es mi relación con Dios Padre?

- ¿Cómo está mi encuentro personal con Jesucristo Resucitado?

- ¿Cómo vivo el amor fraterno que Jesús apremia?

- ¿Cómo contribuyo en la construcción de ese mundo nuevo que Jesús predicó? ¿Qué valores puedo aportar?

\section{La misión que me toca: ser Iglesia en el mundo}

Es importante estudiar y conocer a la Iglesia para amarla como Pueblo de Dios y Cuerpo de Cristo, reconociendo en ella flaquezas y fallas, para poder entonces asumir consciente y comprometidamente su misión en el mundo. La reflexión sobre la Iglesia debemos realizarla no desde la postura de quien está "afuera" y no forma parte de la Iglesia, sino reconociéndonos parte del Pueblo de Dios, parte de la Iglesia.

Pero... ¿Qué es la Iglesia? Aunque lográramos reunir todas las características que definen el perfil de la Iglesia, sabríamos que ella es todo eso y mucho más que eso, porque siendo Pueblo de Dios, siendo de Cristo, es imposible agotar su comprensión, ya que tendríamos que cerrar o agotar el conocimiento del mismo Jesús.

a) La Iglesia es

- Pueblo de Dios, comunidad de fe, esperanza y caridad.

- Signo y sacramento de la presencia salvadora y liberadora de Cristo dentro de su pueblo.

- Misión actualizada de Cristo en el hoy de la historia de la humanidad.

La Iglesia es pueblo de Dios, formado por todos los hombres y mujeres que creen en Jesús, esperan la realización de sus promesas y 
que, sabiendo que son hijos amados por Cristo hasta el extremo (Jn 13,1) se reúnen en comunidades vivas, hermanadas por la Palabra de Dios, por el amor fraterno, por la comunión en el Cuerpo Eucarístico de Cristo, en la oración, en el compartir los bienes con los pobres y necesitados, en la convivencia simple y alegre, tanto en las iglesias como en los encuentros en las casas (Hch 2,42-47).

La Iglesia es signo visible, sacramento de acción y presencia salvadora y liberadora de Cristo dentro de su pueblo. En la medida en que la Iglesia es el espacio en que los pobres se sienten acogidos en su casa, como pueblo amado en Cristo por el Padre, ella realiza la parábola de Cristo (Lc 14, 15-24), en la que nos pide que busquemos y recojamos "a los pobres, los alejados, los ciegos, los mancos" para que ocupen un lugar en la sala del banquete del Reino.

La Iglesia, siendo la comunidad de los pobres (Lc 10,21), cumple con el mandato de Cristo: "Ustedes recibieron la fuerza del Espíritu Santo para ser mis testigos" en todas las regiones del mundo (Hch 1,8), y es, efectivamente, signo y sacramento de la presencia amorosa y del amor actuante de Jesús, convocando, reuniendo y liberando a su pueblo a través de la vida y de la acción de aquellos que creen en Él.

\section{b) La misión de la Iglesia}

La Iglesia tiene por excelencia una misión evangelizadora: "Vayan y hagan que todos los pueblos sean mis discípulos..." (Mt 28,19). El apóstol Pablo, uno de los mayores militantes del Reino de Dios proclamados por Jesús, llegó a exclamar: “¡Ay de mí si no anunciara el Evangelio!" (1 Cor 9,16). Jesús confía a la Iglesia su propia misión, aquella que el Padre le confiara a Él, de impregnar la historia de la humanidad con los trazos de su proyecto, mediante el anuncio, la acción, el testimonio de vida y la denuncia de las falsas propuestas de solución defendidas por el mundo.

Como Iglesia, la juventud tiene una misión especial. Como afirman los obispos en Medellín: "La juventud es el símbolo de la Iglesia, llamada a una constante renovación de sí misma, o sea, a un incesante rejuvenecimiento" (Medellín 5,12). Por eso esta misma juventud debe profundizar el conocimiento y sentido de pertenencia a la Iglesia, liberadora y profética, y fortalecer su amor y compromiso de renovarla constantemente. 
c) Profundizando algunos aspectos.

- ¿Cómo vemos a la Iglesia?

- ¿Qué limites, tendencias y desafíos nos presenta?

- ¿Qué características de la Iglesia podemos reconocer en nuestra experiencia comunitaria?

- ¿Cómo influyen en nuestra vida, en la comunidad y en la sociedad los diferentes modelos de Iglesia?

- ¿Qué Iglesia quiero? ¿Cuáles serían sus características fundamentales?

- ¿Qué necesito reforzar y rever en mis acciones y actitudes en cuanto miembro de la Iglesia? ¿Qué tendencias debo reforzar? ¿Cuáles cambiar?

- ¿Qué puedo hacer en mi comunidad para construir una Nueva Iglesia-Pueblo-Comunidad?

- ¿Cuál es la misión que la Iglesia debe asumir frente a los nuevos desafíos de la realidad?

- ¿Cuál es la misión de los cristianos en la construcción de una sociedad justa y fraterna?

- ¿Qué relación encuentro entre la fe y el compromiso social (político, económico, cultural, etc.)? ¿Qué desafíos se me presentan en este sentido?

\section{Mi camino: elaborando mi proyecto}

Casi todo militante vive una vida agitada y con expectativas de realizar sus sueños y deseos, para proyectarse en nuevos horizontes. Este Proyecto personal de Vida elaborado deberá estar abierto a los cambios, a las adaptaciones, en la medida que vayan surgiendo situaciones nuevas. Él nos obliga a tomarnos la vida en serio y nos hace entrar en un proceso de autenticidad y crecimiento personal. Hay que prever, por eso, momentos concretos de evaluación (reformulación, readaptación, maduración...) del proyecto de vida.

Lo principal del proyecto de vida es que las decisiones tomadas y reflexionadas nos lleven a una mejor y más plena realización personal, a partir de nuestro compromiso en la lucha por una nueva vida. Cuando una constructora va a realizar una calle, comienza colocando las 
marcas o cordones que sirven de puntos de referencia para saber por dónde va a pasar la calle. Como constructores de nueva vida, también nosotros debemos colocar "las marcas o cordones" para orientar nuestra acción. Es preciso entonces, redescubrir y reanimar en nosotros, los motivos de nuestra vida y las prioridades que buscamos. Es preciso reflexionar siempre sobre todo lo que estamos haciendo.

Nuestro Proyecto de Vida debe ser escrito, aprovechando los recursos que tenemos, con una profunda simpleza e interioridad. Nos ayudan las siguientes orientaciones:

- Redactarlo con claridad.

- Retomar las reflexiones y anotaciones hechas a lo largo del proceso.

- Procurar concretizar bien lo que se propone.

- Sintetizar las ideas en pocas líneas.

- Confrontarlo siempre con la realidad en la que uno está actuando.

- Procurar que sea muy concreto, madurando estrategias que sean de corto, mediano y largo plazo.

- Incluir todas las dimensiones de la persona humana.

La elaboración del proyecto de vida es algo muy personal. Pero es muy recomendable que no se haga solo. Debe buscarse y solicitar la ayuda de un/a acompañante (un/a animador/a, psicólogo/a, amigo/a, religioso/a, sacerdote, adulto/a...). Alguien que sea de nuestra confianza.

El proyecto elaborado necesita prever, también, la forma como será evaluado. Es un proyecto que debe representarse, que debe defenderse. Hay aspectos que nunca cambiarían; otros exigirán adaptación, pero una adaptación reflexionada con mucha seriedad. 